\title{
Padrão de fraturas da região da Serra dos Órgãos (RJ) e sua relação com a tectônica mesozóico-cenozóica do sudeste do Brasil
}

\author{
Marcos Eduardo Hartwig ${ }^{1} \&$ Claudio Riccomini $^{2}$
}

\begin{abstract}
Resumo A Serra dos Órgãos, nome local dado a Serra do Mar entre as cidades de Petrópolis e Teresópolis, Estado do Rio de Janeiro, é uma das feições fisiográficas mais notáveis do sudeste brasileiro. Com elevações superiores a $2.200 \mathrm{~m}$ acima do nível do mar, esta feição, acompanha as estruturas do embasamento pré-cambriano, constituído de rochas metamórficas intrudidas por várias gerações de rochas granitóides, incluídas no Terreno Oriental do setor central da Faixa Ribeira. Após um longo período de quiescência tectônica, a atual região costeira do sul-sudeste brasileiro foi palco de importante processo de reativação tectônica, manifestado a partir do Jurássico, que culminou com a abertura do Oceano Atlântico Sul. A análise do padrão de fraturas da Serra dos Órgãos, na porção correspondente ao Parque Nacional da Serra dos Órgãos (PARNASO), indicou provável vigência de cinco fases tectônicas de deformação, desde o Neoproterozóico-Cambriano até o Recente, que em parte apresentam relações com deformações anteriormente identificadas na região sudeste do Brasil: (1) transcorrência sinistral de direção E-W e idade neoproterozóica-cambriana; (2) transcorrência sinistral de direção E-W e idade eocretácea; (3) transcorrência sinistral de idade neocretácea-paleocena; (4) distensão de direção NW-SE, de idade eocena; e (5) compressão E-W, de idade holocena.
\end{abstract}

Palavras-chave: tectônica rúptil, fraturas, Serra dos Órgãos, Rio de Janeiro, sudeste do Brasil.

\begin{abstract}
Fracture Pattern in the Serra dos Órgãos range, Rio de Janeiro state and its relationship to the mesozoic-cenozoic tectonics of southeastern Brazil. The Serra dos Órgãos range, between Petrópolis and Teresópolis cities, Rio de Janeiro State, is one of the most remarkable physiographic features of southeastern Brazilian coast. This feature, part of the Serra do Mar coastal range, with summits over 2.200 m.a.s.l, follow Precambrian basement structures constituted of metamorphic rocks intruded by several generations of granitoid rocks, included in the Oriental Terrane of the central segment of the Ribeira folded belt. After a long period of tectonic quiescence, the present-day southeastern Brazilian coastal region was subjected to an important process of tectonic reactivation, manifested since Jurassic times, which culminated with the opening of South Atlantic Ocean. Analysis of the fracture pattern of the Serra dos Órgãos range in the region of the Serra dos Órgãos National Park (Parque Nacional da Serra dos Órgãos - PARNASO) indicated the existence of five tectonic deformation phases, active from Neoproterozoic-Cambrian until the Recent times, in part correlatable with previously recognized deformations in southeastern Brazil: (1) Neoproterozoic-Cambrian left-lateral EW-trending strike-slip; (2) and (3) Early Cretaceous and Late Cretaceous to Paleocene left-lateral E-W-trending strike-slip; (4) Eocene NW-SE-trending extension; and (5) Holocene E-W-trending compression.
\end{abstract}

Keywords: brittle tectonics, fractures, Serra dos Órgãos range, Rio de Janeiro, southeastern Brazil.

INTRODUÇÃO A evolução tectônica da atual região costeira do sudeste do Brasil é marcada por um importante processo de reativação, manifestado a partir do Jurássico, que culminou com a abertura do Oceano Atlântico Sul (Almeida 1967, 1969). Este fenômeno foi responsável pelo desenvolvimento de bacias costeiras e continentais, bem como de porções soerguidas adjacentes, que caracterizam as serras do Mar e da Mantiqueira, e farto magmatismo de caráter básico a alcalino (Almeida 1976, Asmus \& Ferrari 1978, Hasui et al. 1978, Melo et al. 1985, Almeida 1986, Riccomini 1989, Almeida \& Carneiro 1998, Riccomini \& Assunção 1999, Ferrari 2001, Riccomini et al. 2004, Riccomini et al. 2005, Zálan \& Oliveira 2005).
A compreensão dos mecanismos e eventos tectônicos envolvidos nesse fenômeno depende, entre outros fatores, da caracterização e cadastramento das estruturas tectônicas a eles relacionados e também da determinação de paleocampos de tensões, a partir de falhas e respectivas estrias de atrito (Hancock 1985, Petit 1987, Angelier 1994, Stewart \& Hancock 1994, Doblas et al. 1997), juntas (Hancock \& Engelder 1989, Caputo 1991 e 1995) e diques de natureza e idades variadas (Anderson 1951, Zoback 1992, Geoffroy et al. 1993). Estudos dessa natureza desenvolvidos na região costeira (Ferrari 2001) e nas bacias do Rift Continental do sudeste do Brasil (v.g. Riccomini 1989, Salvador \& Riccomini 1995, Ferrari 2001, Riccomini et al

1 - Universidade de São Paulo, Instituto de Geociências, Programa de Pós-Graduação em Geoquímica e Geotectônica, São Paulo (SP), Brasil. E-mail: marcoshartwig@yahoo.com.br

2 - Universidade de São Paulo, Instituto de Geociências, Departamento de Geologia Sedimentar e Ambiental e Programa de Pós-Graduação em Geoquímica e Geotectônica, bolsista de produtividade em pesquisa do CNPq, São Paulo (SP), Brasil. E-mail: riccomin@usp.br 
2004), bem como em porções elevadas da Serra da Mantiqueira (Hiruma et al. 2001, Modenesi-Gauttieri et al. 2002, Chiessi, 2004) e da Bocaina (Hiruma 2007), demonstraram a existência de diferentes eventos deformacionais, de expressão regional, durante o Mesozóico e o Cenozóico.

Neste trabalho foram estudadas as fraturas presentes em um setor da Serra do Mar, na porção correspondente ao Parque Nacional da Serra dos Órgãos (PARNASO), Estado do Rio de Janeiro (Fig. 1). O estudo teve como objetivos: (1) a caraterização geométrica, determinação de eventos de fraturamento e respectivas paleotensões a partir do padrão de distribuição de fraturas (falhas e juntas) e diques de rochas básicas; (2) verificar se o padrão de fraturas e paleotensões é peculiar ao contexto geomorfológico do PARNASO, uma região de cimeira da Serra do Mar; e (3) correlacionar os eventos deformacionais identificados com o quadro tectônico mesozóico-cenozóico da região sudeste do Brasil.

O PARNASO é uma unidade de conservação criada em 1939, com área de aproximadamente 105 $\mathrm{km}^{2}$, densamente recoberta por um remanescente da Mata Atlântica, cuja extensão original ocupava quase toda costa brasileira (Schäffer \& Prochnow 2002). O estudo consistiu essencialmente de levantamentos de campo, com reconhecimento litológico, cadastramento e análise de dados estruturais. Embora o PARNASO esteja localizado em uma região ínvia e de difícil acesso, procurou-se efetuar observações bem distribuídas em área e obter o maior número possível de dados estruturais nas diferentes exposições de rochas estudadas.

CONTEXTO GEOLÓGICO E GEOMORFOLÓGICO A Serra dos Órgãos, localizada entre as cidades de Petrópolis e Teresópolis, Estado do Rio de Janeiro, corresponde a um segmento da Serra do Mar que constitui uma das mais destacadas feições orográficas da borda sulsudeste do continente sul-americano, cuja direção geral acompanha a orientação NE-ENE das estruturas do embasamento costeiro (Hasui et al. 1975, Almeida 1976). Esta feição está instalada no domínio da Faixa Ribeira, de idade pré-cambriana a eopaleozóica, parte do Sistema Orogênico Mantiqueira (Hasui et al. 1975, Hasui \& Oliveira 1984, Trouw et al. 2000, Heilbron \& Machado 2003).

Depois de um longo período de consolidação, a atual região costeira do sudeste do Brasil foi palco de um importante processo de reativação tectônica, manifestado a partir do Jurássico, que culminou com a abertura do Oceano Atlântico Sul (Almeida 1967, 1969). Este fenômeno foi responsável pelo desenvolvimento de bacias costeiras e continentais, porções soerguidas adjacentes das Serras do Mar e Mantiqueira, e abundante magmatismo de caráter básico a alcalino (Almeida 1976, Asmus \& Ferrari 1978, Melo et al. 1985, Almeida 1986, Riccomini 1989, Gallagher et al. 1994, Almeida \& Carneiro 1998, Ferrari 2001, Riccomini et al. 2004, Riccomini et al. 2005, Zálan 2005). O conjunto das bacias continentais do sudeste brasileiro foi denominado de "Sistema de Rifts da Serra do Mar" por Almeida (1976) e de "Rift Continental do Sudeste do Brasil" por Riccomini (1989).

$\mathrm{Na}$ região do PARNASO as litologias précambrianas e eopaleozóicas estão individualizadas em quatro unidades básicas: a) Complexo Rio Negro, que congrega migmatitos heterogêneos e biotita gnaisses graníticos; b) Batólito Serra dos Órgãos, representado por biotita granitos a granodioritos gnáissicos; c) leucogranitos gnáissicos; e d) granitos pós-colisionais (granitos Andorinha e Nova Friburgo). Diques de diabásio de idade mesozóica cortam as unidades anteriores (Fig. 2).

O relevo no PARNASO é marcado por um planalto nivelado em torno de $2.000 \mathrm{~m}$, do qual se sobressaem elevações que ultrapassam $2.200 \mathrm{~m}$, além de uma imensa es-

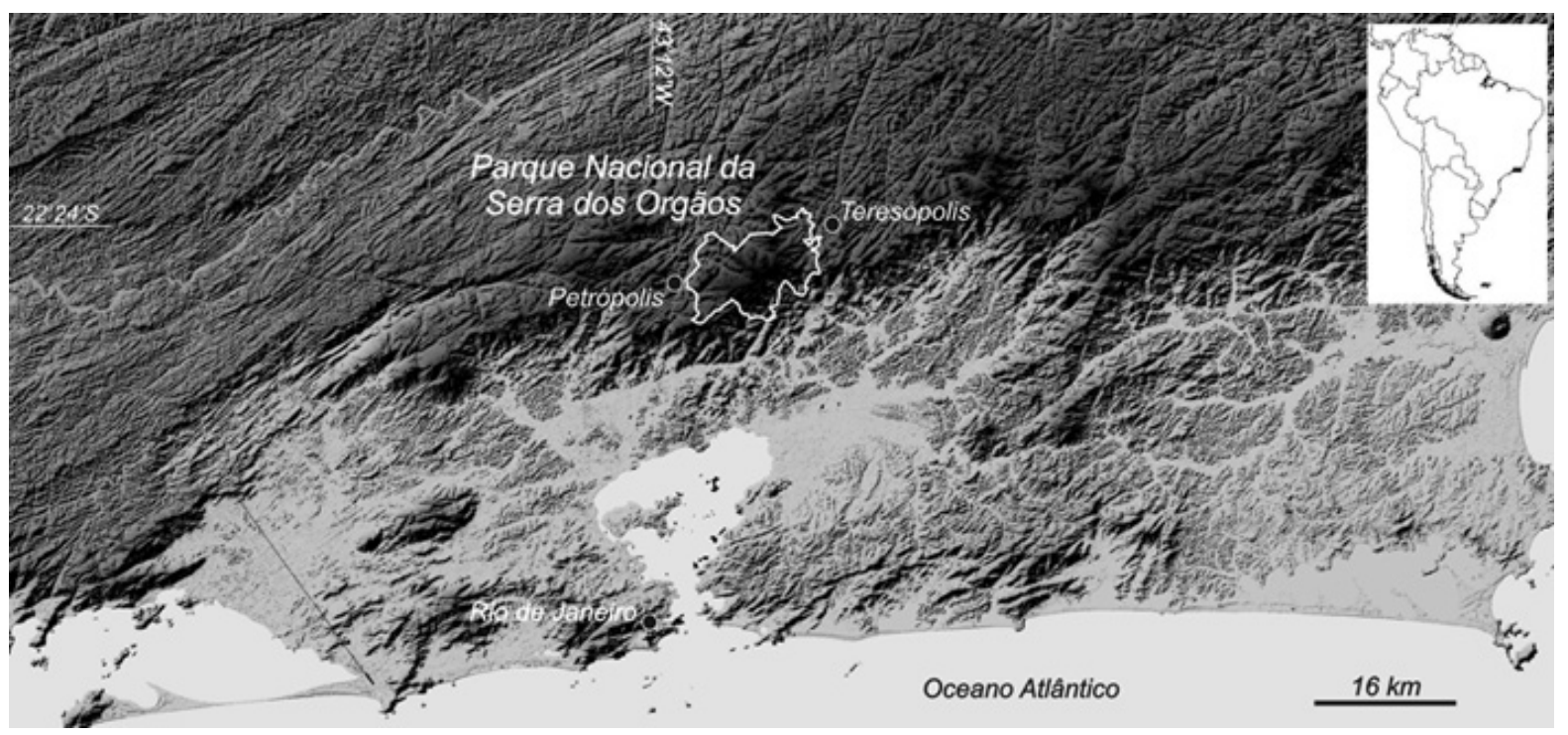

Figura 1 - Localização do Parque Nacional da Serra dos Órgãos - PARNASO, sudeste do Brasil. A imagem apresenta as principais feições fisiográficas da costa emersa do Estado do Rio de Janeito. Fonte: Shuttle Radar Topography Mission (SRTM-90m). 


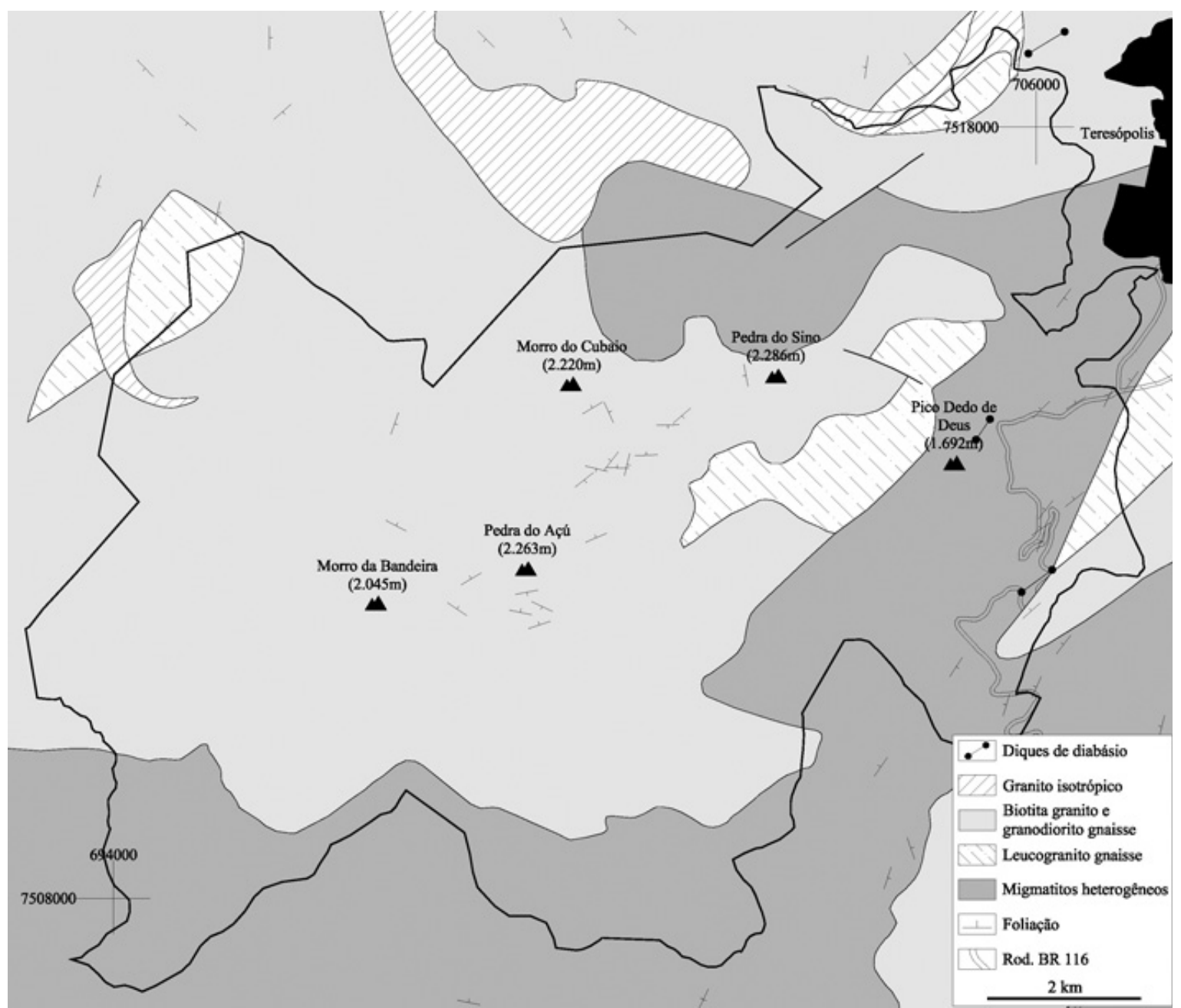

Figura 2 - Mapa geológico simplificado do Parque Nacional da Serra dos Órgãos (PARNASO), modificado de Penha et al. (1979), Pinto et al. (1980), Penha et al. (1981) e Ferrari et al. (1981). Sistema de coordenadas UTM, Zona $23 \mathrm{~K}$.

carpa escalonada de direção ENE, abatida para sul-sudeste (Ruellan 1944, King 1956, Zalán 2004, Hartwig 2006).

MÉTODOS O levantamento de campo enfocou a análise estrutural rúptil, compreendendo a descrição de afloramentos e cadastramento de dados pareados de falhas e respectivas estrias de atrito, juntas e diques básicos, de idades variadas. Estes dados foram tratados a partir de estereogramas construídos com base no diagrama de Schmidt-Lambert, hemisfério de referência inferior. Em todos os casos empregou-se a representação polar, exceto naqueles representados por falhas/estrias de atrito e juntas de alívio, nos quais se empregou a representação ciclográfica. Em função do ângulo de mergulho, as estruturas foram descritas em termos de alto ângulo $\left(>65^{\circ}\right)$ ou de baixo ângulo $\left(<40^{\circ}\right)$.

Juntas são fraturas que à escala de observação de campo não exibem preenchimento e nenhum tipo de deslocamento apreciável (Hancock 1985, Dunne \& Hancock 1994). Segundo os experimentos laboratoriais, as juntas se arranjam simetricamente em relação aos eixos de tensão principais (Dunne \& Hancock
1994), fato que permite utilizá-las como indicadores tectônicos. Em função das condições mecânicas de ruptura são geradas distintas classes genéticas de juntas que podem ser determinadas a partir da sua caracterização in loco, o que possibilita aferir a orientação dos paleoesforços vigentes (Hancock 1985). Com o transcurso de sucessivos eventos deformadores, distintas famílias de juntas podem ser originadas. A individualização destas famílias é realizada em função de suas relações, o que possibilita estabelecer o encadeamento cronológico dos eventos tectônicos superpostos (Dunne \& Hancock 1994). Juntas de expansão ou de alívio, que são estruturas paralelas ou subparalelas à superfície natural do terreno, ocasionadas pela remoção da pressão confinante de soterramento (Price 1966), podem se desenvolver em áreas de topografia pronunciada.

Falhas são fraturas nas quais existe deslocamento visível por cisalhamento paralelo à superfície da fratura (Davis \& Reynolds 1996). A fim de se conhecer o sentido de movimento ao longo de um plano de falha, o que permite deduzir o campo de tensões por ocasião de sua geração, três critérios principais são usados: a) 
marcadores estratigráficos (ex: camadas sedimentares, seixos deslocados etc); b) dobras de arrasto próximas à falhas; e c) uma grande variedade de feições assimétricas observáveis no plano de falha (Petit 1987, Angelier 1994, Doblas et al. 1997). Dentre os métodos de inversão, que buscam reconstituir os paleoesforços associados a uma determinada população de falhas, um dos mais utilizados é o método gráfico dos diedros retos (Angelier \& Mechler 1977), empregado neste trabalho.

Diques são corpos tabulares que comumente cortam as estruturas de suas rochas encaixantes e cuja razão espessura/comprimento é da ordem de $10^{-2}$ a $10^{-4}$ (Rickwood 1990, Best \& Christiansen 2001). Diques são considerados excelentes indicadores tectônicos, já que se colocam ortogonalmente ao eixo de tensão mínimo $\sigma_{3}$ (Anderson 1951), sobretudo quando constituem enxames - agrupamentos de corpos de mesma idade e geograficamente relacionados, além de serem constituídos por rochas relativamente fáceis de serem datadas por meio de métodos isotópicos (Feraud \& Campredon 1983). Geoffroy et al. (1993) encontraram boa concordância entre $\sigma 1$ e $\sigma 2$ determinados tanto através da orientação de diques, como a partir do movimento de falhas, para um mesmo campo de esforços.

As direções de paleotensões obtidas são expressas em termos dos esforços horizontais máximo ( $\mathrm{SH}$ máx) ou mínimo (Shmín). A direção de SHmáx corresponde à direção do eixo de tensão principal máximo $(\sigma 1)$, no caso dos regimes transcorrente e compressivo, ou à direção do eixo de tensão principal intermediário $(\sigma 2)$, no caso de regime distensivo. A direção de Shmín, por sua vez, corresponde à direção do eixo de tensão principal mínimo $(\sigma 3)$, no caso dos regimes distensivo e transcorrente, e à direção do eixo de tensão principal intermediário $(\sigma 2)$, no caso de regime compressivo.

RESULTADOS As atividades de campo envolveram o cadastramento de cerca de 1800 dados de juntas, falhas/estrias de atrito e diques de rochas básicas distribuídos em quarenta e cinco sítios de investigação. Dados de juntas são preponderantes, uma vez que falhas/estrias de atrito e diques foram observados apenas localizadamente. O mapa apresentado na figura 3 , cujos aspectos geológicos correspondem aos da figura 2, oferece um

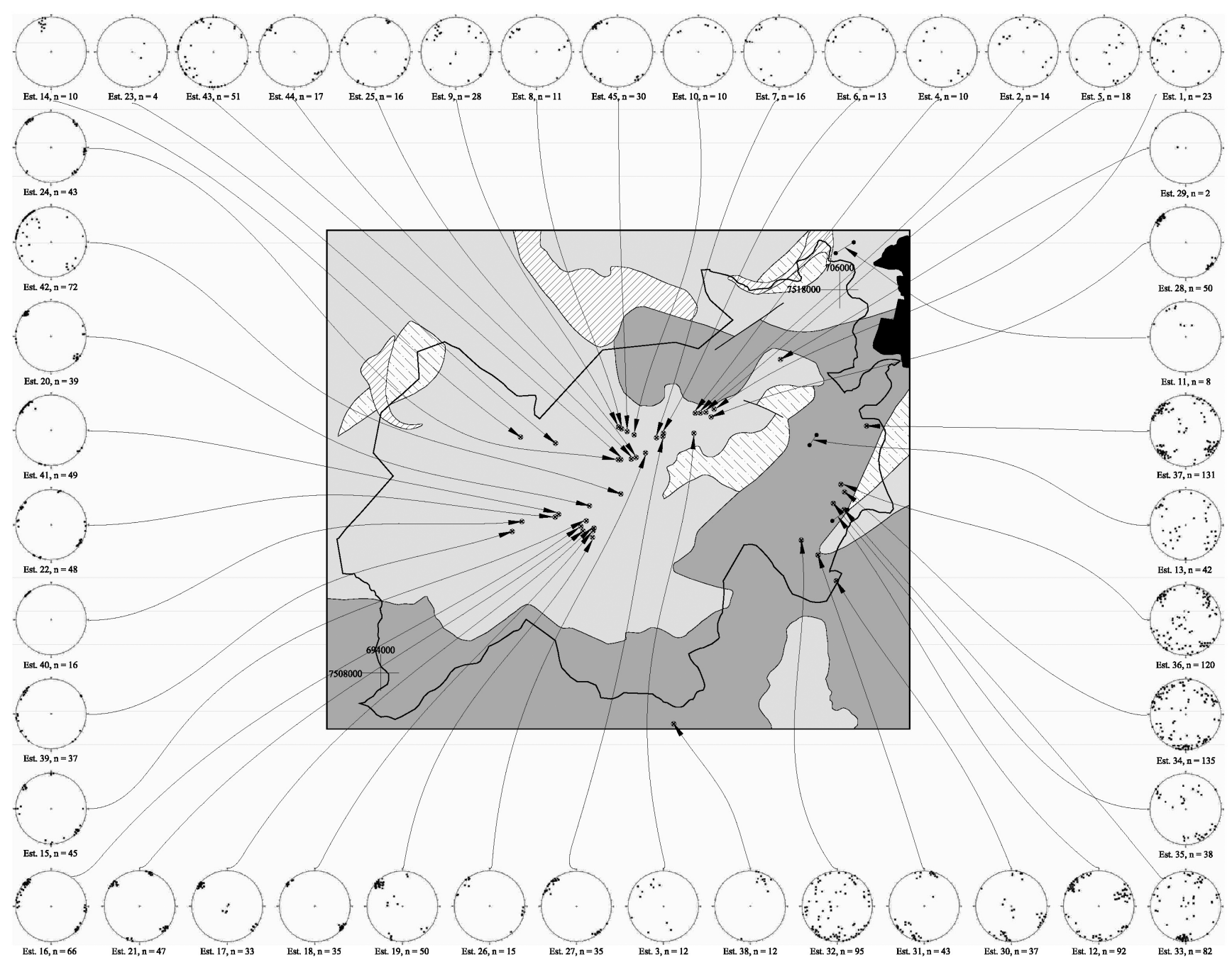

Figura 3 - Distribuição dos dados de juntas no PARNASO. Projeção polar, diagramas Schmidt-Lambert, hemisfério inferior. Coordenadas UTM (Zona 23K). 
panorama dos dados de juntas coletados em campo.

Juntas O espaçamento entre juntas nas diferentes exposições estudadas mostrou-se heterogêneo, em geral variando de decimétrico a métrico. Constatou-se que a maioria das juntas identificadas apresenta valores altos de mergulho, enquanto que valores baixos correspondem a juntas de alívio.

Dos sítios investigados, 34 dos 45 ocorrem sobre veios e porções aplíticas do Batólito Serra dos Órgãos.

Com base na figura 3 , a tabela 1 procura retratar a distribuição do número de juntas por famílias determinadas em cada sítio de investigação. Considerando-se oito classes de direções preferenciais, espaçadas de $22,5^{\circ}$, as famílias de juntas de direção NE-SW, NW-SE, E-W e WNW-ESE, concentram noventa por cento dos dados obtidos, além de terem sido verificadas em um maior número de sítios de investigação. As famílias de juntas das demais direções, NNE-SSW, N-S, ENE-WSW e NNWSSE, apresentam frequências significativamente menores. Em função da proximidade geográfica, litotipo e orientação das famílias de juntas, foram caracterizados oito domínios estruturais, designados de $\mathrm{A}$ a $\mathrm{H}$, figura 4. Nesta figura observa-se que:

a) as famílias de juntas sistemáticas de direção NE-SW e NW-SE, subverticais ocorrem em todos os domínios, alternando-se nas estações 11, 23, 28, 29 e 31;

b) famílias de direção WNW-ESE e N-S, subverticais concentram-se principalmente nos domínios A, B e C, enquanto a primeira família ainda é identificada nas estações 31 e 38 ;

Tabela 1 - Frequência de juntas por famílias determinadas em cada sítio investigado.

\begin{tabular}{|c|c|c|c|c|c|c|c|c|c|c|}
\hline \multirow{2}{*}{ 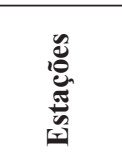 } & \multicolumn{9}{|c|}{ Trend preferencial das famílias de juntas } & \multirow{2}{*}{ 承 } \\
\hline & NE-SW & NW-SE & E-W & $\begin{array}{l}\text { WNW- } \\
\text { ESE }\end{array}$ & $\begin{array}{l}\text { NNE- } \\
\text { SSW }\end{array}$ & $\mathrm{N}-\mathrm{S}$ & $\begin{array}{l}\text { ENE- } \\
\text { WSW }\end{array}$ & $\begin{array}{l}\text { NNW- } \\
\text { SSE }\end{array}$ & $\begin{array}{c}\text { Juntas de } \\
\text { Alívio }\end{array}$ & \\
\hline 1 & 13 & 6 & & & & & 3 & & 1 & 23 \\
\hline 2 & 8 & & & 4 & & & 2 & & & 14 \\
\hline 3 & 9 & 2 & & & & & & & 1 & 12 \\
\hline 4 & 8 & 2 & & & & & & & & 10 \\
\hline 5 & 6 & 8 & & & & & & & 4 & 18 \\
\hline 6 & 8 & 5 & & & & & & & & 13 \\
\hline 7 & 10 & 4 & 2 & & & & & & & 16 \\
\hline 8 & 7 & & & & & & & 4 & & 11 \\
\hline 9 & 17 & 7 & & & & 2 & & & 2 & 28 \\
\hline 10 & 6 & 4 & & & & & & & & 10 \\
\hline $11^{*}$ & & & & & & & 5 & & 3 & 8 \\
\hline $12^{*}$ & 38 & 36 & 9 & & & & 9 & & & 92 \\
\hline $13^{*}$ & 21 & 11 & 3 & & & & & & 7 & 42 \\
\hline 14 & & & & & & & 10 & & & 10 \\
\hline 15 & 31 & & 9 & & & 5 & & & & 45 \\
\hline 16 & 53 & & & & & 13 & & & & 66 \\
\hline 17 & 29 & & & & & & & & 4 & 33 \\
\hline 18 & 35 & & & & & & & & & 35 \\
\hline 19 & 40 & & & 6 & & & & & 4 & 50 \\
\hline 20 & 32 & & & & & 7 & & & & 39 \\
\hline 21 & 27 & & & 20 & & & & & & 47 \\
\hline 22 & 28 & & & 11 & & 9 & & & & 48 \\
\hline 23 & $\frac{20}{2}$ & & & & & & & & 2 & 4 \\
\hline 24 & 23 & 9 & & & & 11 & & & & 43 \\
\hline 25 & & & & 8 & 8 & & & & & 16 \\
\hline 26 & 7 & & & & 8 & & & & & 15 \\
\hline 27 & 25 & & & & 10 & & & & & 35 \\
\hline 28 & 50 & & & & & & & & & 50 \\
\hline 29 & 1 & & & & & & & & 1 & 2 \\
\hline 30 & & & & 20 & 12 & & & & 5 & 37 \\
\hline 31 & & 12 & & 25 & & & 5 & & 1 & 43 \\
\hline 32 & 28 & 32 & 16 & & & 10 & & & 9 & 95 \\
\hline 33 & 11 & & 42 & 13 & & & & 7 & 9 & 82 \\
\hline 34 & 38 & 40 & 40 & & 10 & & & & 7 & 135 \\
\hline 35 & 22 & 5 & 5 & & & & & & 6 & 38 \\
\hline 36 & 46 & 52 & 8 & & & & & & 14 & 120 \\
\hline 37 & 72 & 54 & & & & & & & 5 & 131 \\
\hline 38 & & & & 12 & & & & & & 12 \\
\hline 39 & 25 & 7 & & & & 5 & & & & 37 \\
\hline 40 & 16 & & & & & & & & & 16 \\
\hline 41 & 44 & & & 5 & & & & & & 49 \\
\hline 42 & 46 & 7 & & & 19 & & & & & 72 \\
\hline 43 & & 20 & 10 & & 12 & & 9 & & & 51 \\
\hline 44 & 17 & & & & & & & & & 17 \\
\hline 45 & 25 & 5 & & & & & & & & 30 \\
\hline TOTAL & 924 & 328 & 144 & 124 & 79 & 62 & 43 & 11 & 85 & 1800 \\
\hline
\end{tabular}




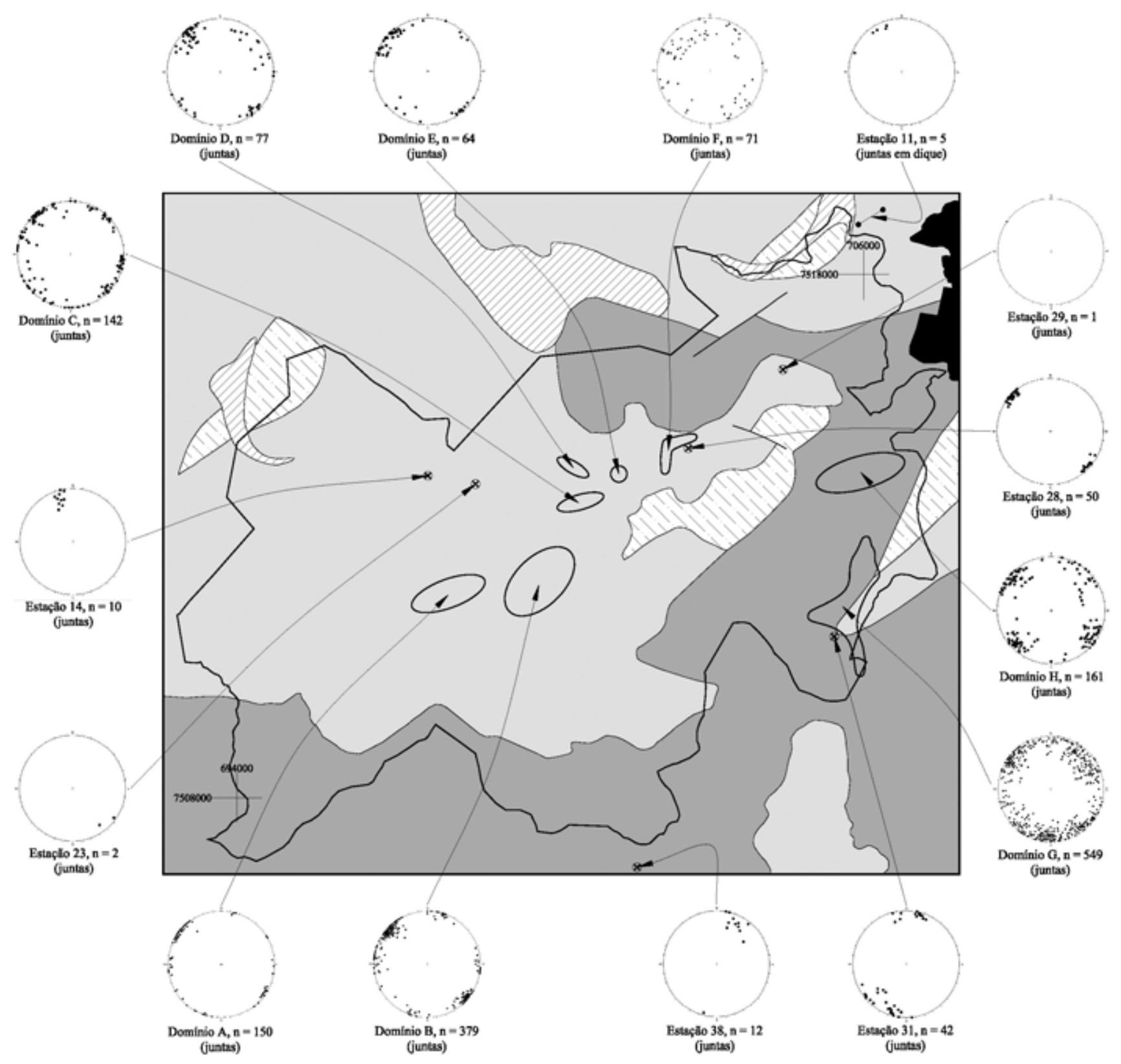

Figura 4 - Domínios estruturais caracterizados no PARNASO. Projeção polar, diagramas Schmidt-Lambert, hemisfério inferior. Coordenadas UTM (Zona 23K).

c) a família de direção E-W, subvertical ocorre nos domínios $\mathrm{B}, \mathrm{C}$ e principalmente $\mathrm{G}$;

d) famílias de direções ENE-WSW e NNESSW, subverticais ocorrem localizadamente no Domínio $\mathrm{C}$, enquanto a primeira família também é encontrada nas estações 14 e 31 .

Dentre as famílias de juntas sistemáticas que ocorrem na área estudada, a de direção NE-SW, subvertical é a principal. Essas juntas encontram-se sem preenchimento ou preenchidas por quartzo (compondo veios), em posição escalonada no interior de veios aplíticos (Fig. 5). Em alguns casos, as juntas não preenchidas dispõem-se paralelamente a diques de diabásio. Essas diferentes formas de ocorrência sugerem que as juntas de direção NE-SW foram geradas ou reaprovei- tadas em diferentes eventos tectônicos.

A segunda família, por ordem de frequência, é a de direção NW-SE, com mergulhos subverticais. As famílias de direções E-W e WNW-ESE, subverticais, ocorrem com frequências semelhantes, embora significativamente menores do que as frequências das famílias de direção NE-SW e NW-SE.

A família de juntas de direção E-W, assim como as famílias NW-SE e NE-SW, encontra-se bem desenvolvida na porção leste-sudeste da área de estudo (domínios $\mathrm{G}$ e $\mathrm{H}$ ), em rochas do embasamento pré-cambriano e também em diques de diabásio eocretáceos.

A família de juntas de direção NNE-SSW, subvertical, ocorre em poucas estações, quase sempre de maneira subordinada às famílias acima descritas. 
A
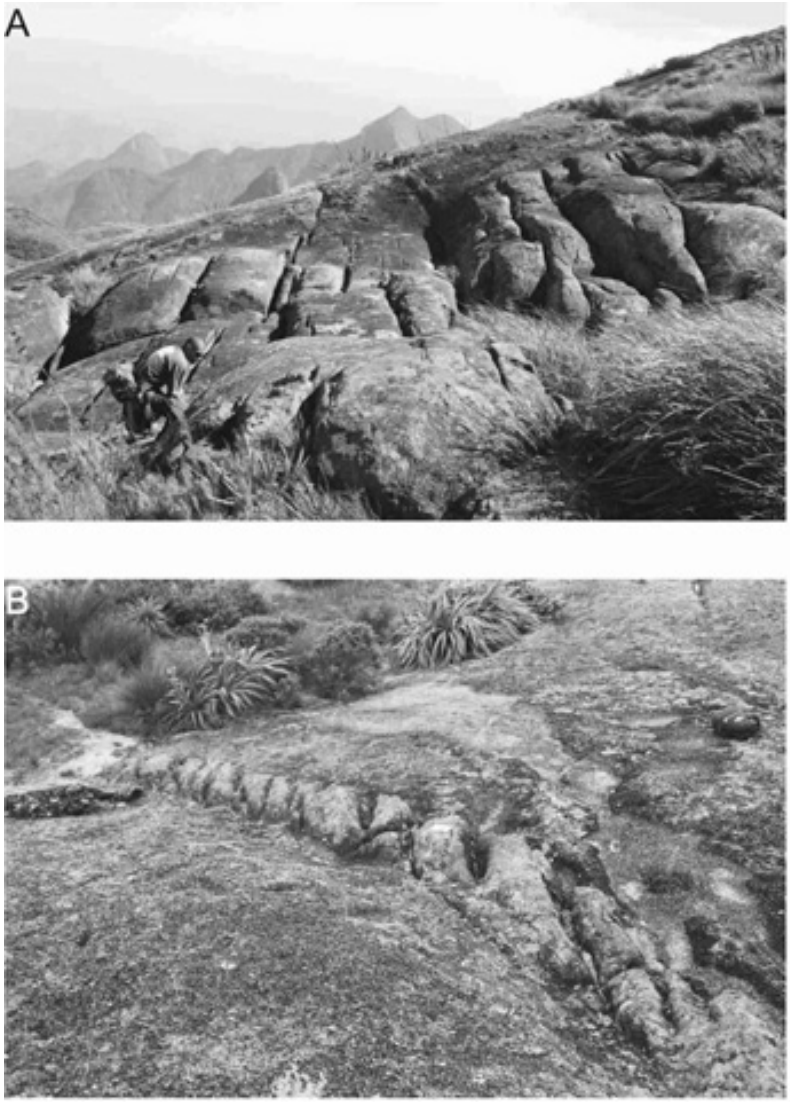

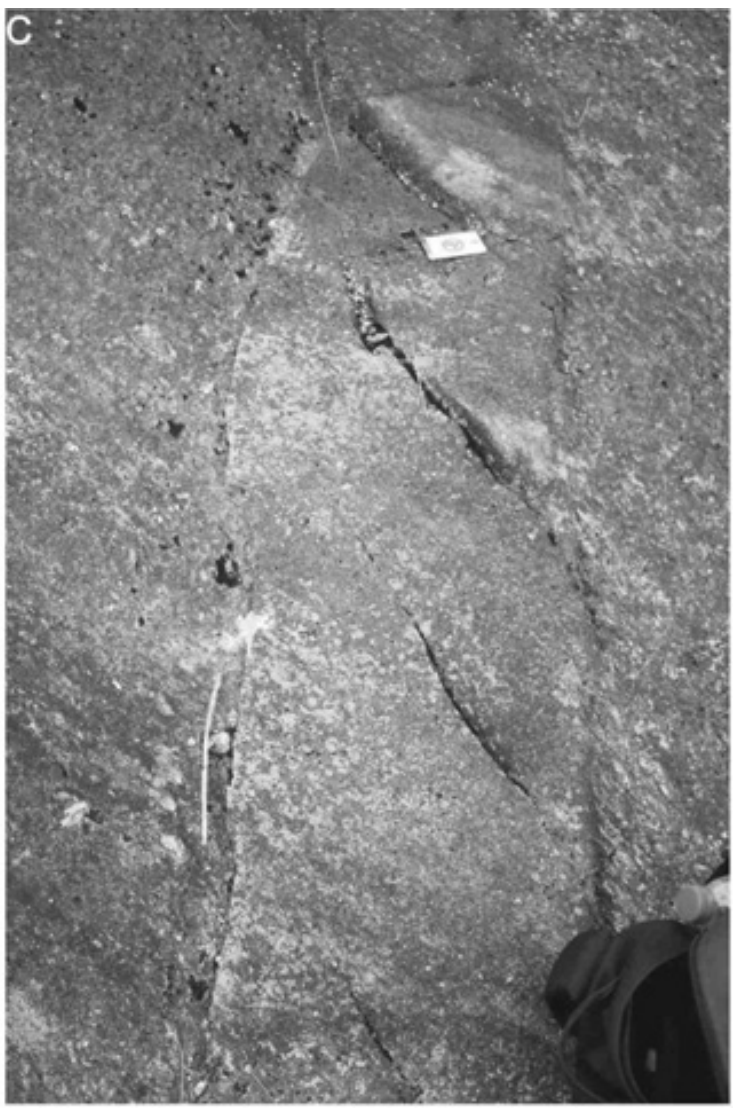

Figura 5 - Juntas distensivas de direção NE-SW, subvertical, em posição escalonada no interior de veios (itens $B$ e C, estações 41 e 9, respectivamente) e porções aplíticas (item A, estação 19) do Batólito Serra dos Órgãos.

As demais famílias, N-S, ENE-WSW e NNW-SSE são pouco frequentes. Vale mencionar que, em um único local (estação 14), na porção centro-noroeste da área estudada, a família ENE-WSW, subvertical, é a única presente.

Além das juntas já descritas, observou-se que, na região do PARNASO, juntas de alívio de ângulo de mergulho suave, paralelas ou subparalelas à superfície, distribuem-se de maneira sistemática na cimeira da Serra dos Órgãos (Fig. 6). Em todas as estações, estas estruturas apresentaram relações mútuas de corte com as outras estruturas.

Com o intuito de analisar a relação entre a distribuição das juntas de alívio e o modelado de relevo atual do PARNASO, os dados de juntas foram sobrepostos aos mapas topográfico (Fig. 7) e de orientação de vertentes (Fig. 8), este último representando a orientação em azimute da reta de maior declive para cada ponto de uma malha regular. Na figura 7 verificou-se significativa correspondência entre as formas do relevo e juntas de alívio, na medida em que estas tendem a ser paralelas à superfície do terreno. Ainda nesta figura observa-se que as estações 1, 3, 17 e 31 não apresentam nenhuma correlação. Na figura 8, buscou-se comparar o rumo de mergulho médio das juntas de alívio com o rumo de mergulho das vertentes. Neste caso, também se observou boa correlação, exceto para as estações 3, 17 e 31 .

Nos diques (estações 11 e 13) ocorrem juntas de

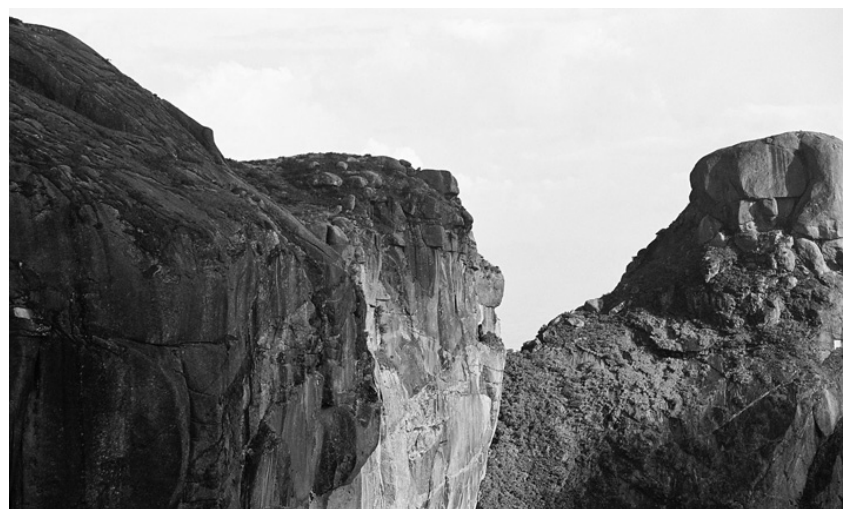

Figura 6 - Juntas de alivio na face sudoeste dos cimos das pedras do Sino (esquerda) e do Garrafão (direita da foto).

direção NW-SE e, menos frequentemente, NE-SW, com ângulos de mergulhos suaves. Estas juntas quando comparadas com o modelado do relevo, visto sob diferentes aspectos (Figs. 7 e 8), revelaram boa correlação, o que sugere que devem corresponder a juntas de alívio.

Falhas Um pequeno número de falhas foi cadastrado na região do PARNASO. Estas estão distribuídas 


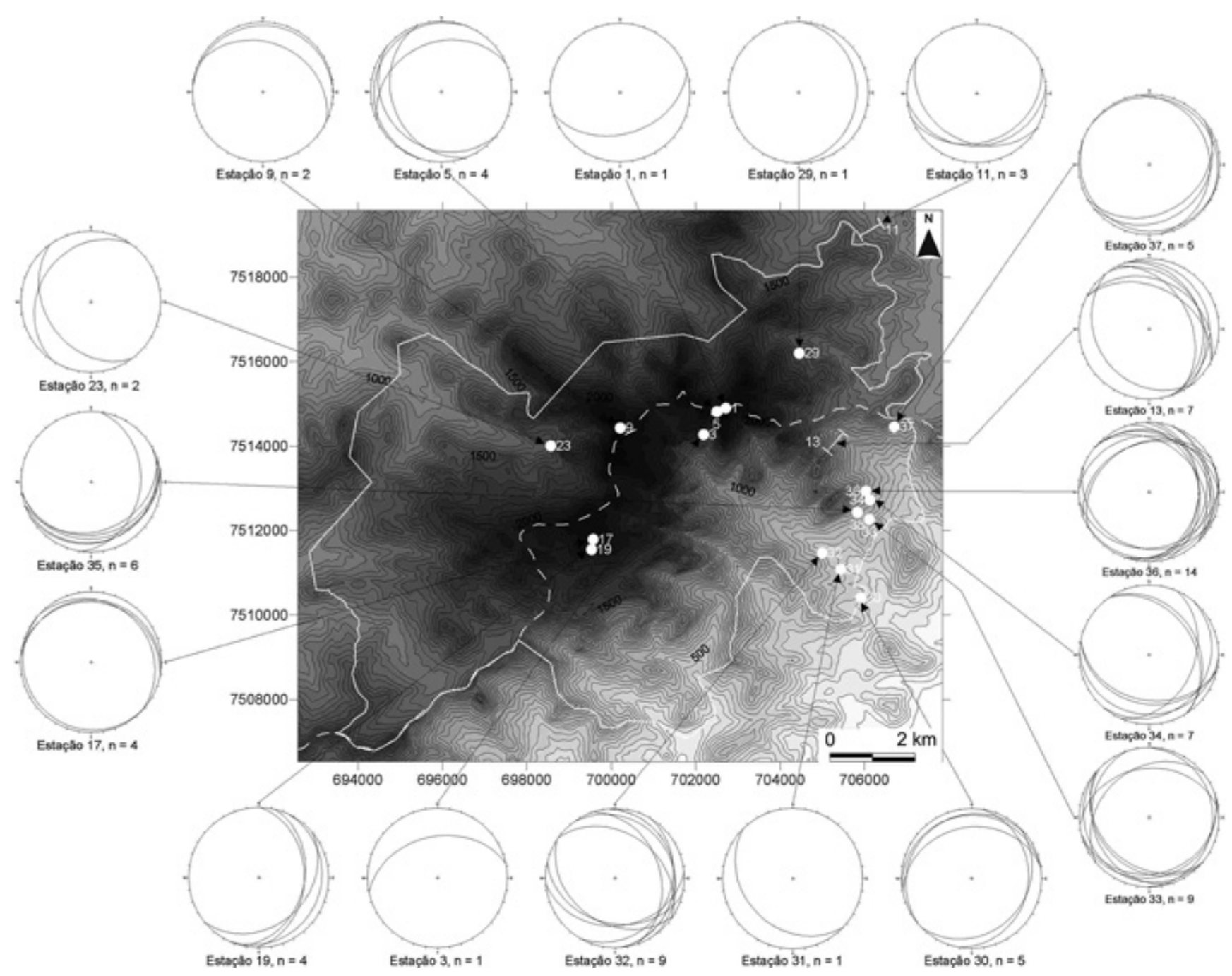

Figura 7 - Mapa de distribuição dos dados de juntas de alívio do PARNASO sobrepostos ao mapa topográfico. Projeções ciclográficas, diagramas Schmidt-Lambert, hemisfério inferior. Coordenadas UTM (Zona 23 $K)$.

em três sítios de investigação, indicados na figura 9. À primeira vista, dois grupos podem ser identificados: de alto e baixo mergulho. Em nenhum dos planos de falhas com estrias de atrito (Fig. 9A, B, C e D) foi possível aferir seu sentido de deslocamento, ao contrário do que ocorre com os planos de falha sem estrias, que deslocam marcadores estratigráficos ou compõem falhas conjugadas (Fig. 9E e F, respectivamente). Planos de falhas sem estrias de atrito foram identificados nas estações 9 e 34. Na estação 9 observou-se dois planos de falhas subverticais, de orientação NE-SW e rejeitos centimétricos, os quais, em função de seus deslocamentos, indicam falhas de caráter dextral e sinistral (Fig. 9E). Na porção centro-leste da área de estudo, estação 34 , em corte da rodovia BR-116, constatou-se que fraturas de direção aproximadamente NE-SW e E-W configuram um sistema de falhas normais conjugadas (Fig. 9F), que afetam migmatitos do embasamento.

Diques Foram identificados e caracterizados três diques de diabásio (estações 11, 12 e 13), com espessuras variando entre 1 e $15 \mathrm{~m}$. Estes corpos apresentam orientação segundo NE-SW e ângulos de mergulho altos ( $\geq$ $80^{\circ}$ ). Seus contatos são retilíneos e abruptos, oblíquos à foliação local.

\section{DISCUSSÃO}

Relações entre as estruturas As relações de corte entre as principais famílias de juntas estudadas puderam ser verificadas em apenas algumas estações (Fig. 10). Apesar dessa limitação, algumas observações e inferências com respeito aos campos de tensões vigentes puderam ser efetuadas:

a) pelo fato de estarem localmente preenchidas por quartzo, ocorrerem associadas e, por vezes, com disposição escalonada restrita à porção interna de veios aplíticos, acredita-se que uma primeira geração de juntas NE-SW, subvertical, tenha ocorrido no Neoproterozóico-Cambriano, sob ação de um regime de esforços com SHmáx segundo a direção NE-SW, horizontal;

b) as juntas da família de direção NE-SW, subverticais, paralelas aos diques de diabásio, estariam por sua 


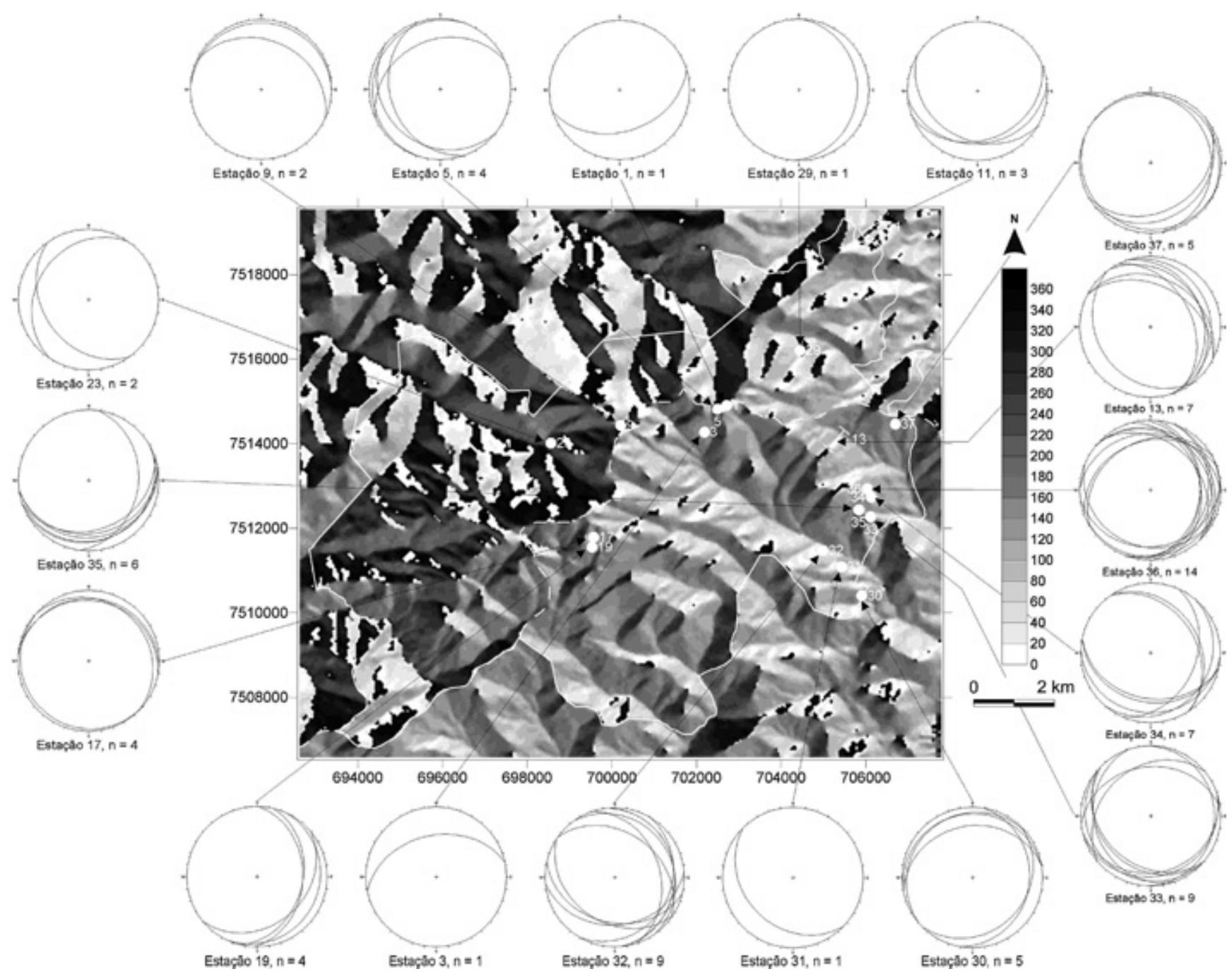

Figura 8 - Mapa de distribuição dos dados de juntas de alivio do PARNASO sobrepostos ao mapa de orientação de vertentes. Projeções ciclográficas, diagramas Schmidt-Lambert, hemisfério inferior. Coordenadas UTM (Zona $23 \mathrm{~K}$ ).

vez relacionadas ao episódio magmático do Eocretáceo (Turner et al. 1995), implicando na ação de um Shmín de direção NW-SE, horizontal; é possível que juntas de direção NE-SW tenham sido ainda geradas ou reaproveitadas em outros estágios da evolução tectônica da área;

c) apesar do número restrito de medidas, na estação 10 (Fig. 10) observou-se que juntas não preenchidas da família NW-SE, subverticais, são sistematicamente deslocadas lateralmente à esquerda pela família NE-SW, sugerindo que estas últimas atuaram localmente como falhas de componente lateral sinistral; o suposto deslocamento implicaria em SHmáx orientado segundo a direção NNE-SSW, horizontal;

d) na estação 19 (Fig. 10) as juntas WNW-ESE e NE-SW não preenchidas exibem relações mútuas de corte, sugerindo tratarem-se de famílias conjugadas de cisalhamento, com SHmáx disposto na bissetriz aguda entre as famílias, na direção ENE-WSW a E-W;

e) a família de juntas de direção E-W não exibe relações conclusivas com respeito às demais famílias, mas seria compatível com uma direção de SHmáx se- gundo E-W, conforme considerado acima, assumindo nesse caso caráter distensivo;

f) a família de juntas de direção NNE-SSW, subvertical, ora é interrompida (estação 26, Fig. 10), ora apresenta relações de deslocamento mútuo com a família de direção NE-SW (estação 27, Fig. 10); no primeiro caso pode ser considerada como uma família de juntas distensivas, formada sob Shmín de direção WNW-ESE; no segundo poderiam ser consideradas como famílias de juntas híbridas, com SHmáx posicionado segundo a direção NNE-SSW a NE-SW, horizontal.

As falhas identificadas, em pequeno número, não permitem maiores considerações de suas relações com as famílias de juntas. Entretanto, para as falhas de baixo ângulo, com estrias em diferentes posições, pode ser sugerida uma origem a partir da reativação de juntas de alívio, em função dos desequilíbrios topográficos existentes nesta região serrana. Os planos de falhas subverticais, sem estrias e de orientação NE-SW, observados na estação 9 , apresentam boa correspondência com o campo de tensões descrito nos itens $d$ e $f$ (acima). 
A

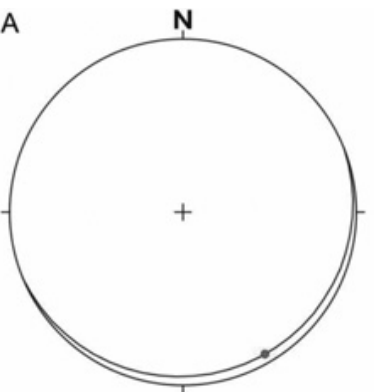

D

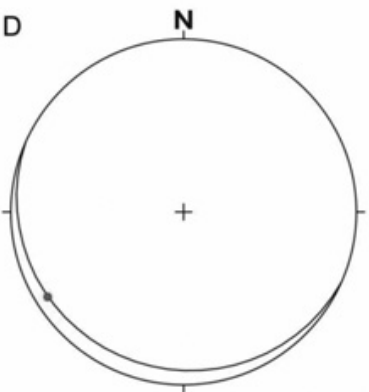

B

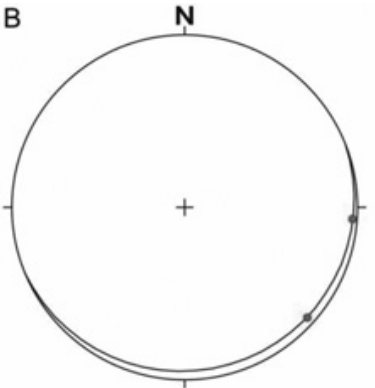

E

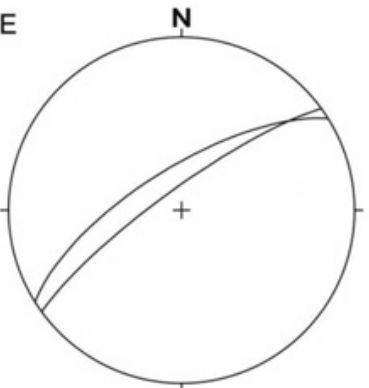

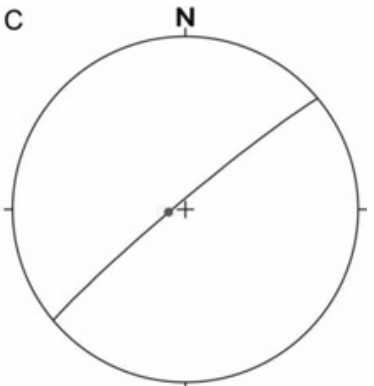

C

$\mathrm{F}$

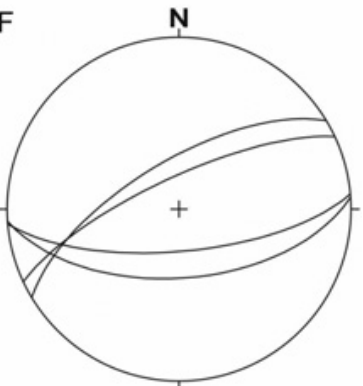

Figura 9 - Projeção ciclográfica de planos de falhas identificados na área de estudo. A, B, C (estação 30) e D (estação 36) - planos de falhas e respectivas estrias de atrito; $E$ - planos de falha sem estrias de atrito, que deslocam marcadores estratigráficos (estação 9); $F$ - falhas normais conjugadas de direções E-W e NE-SW, em corte da rodovia BR-116 (estação 34).

Os planos de falhas normais conjugados de orientação aproximadamente NE-SW e E-W (Fig. 10F) apresentam boa relação com uma distensão NW-SE, horizontal.

As juntas de alívio, observadas em cerca de metade das estações de investigação, apresentaram relações mútuas de corte com as outras estruturas, ângulos suaves de mergulho, disposição paralela a subparalela à superfície atual do relevo, e localização preferencial nas regiões mais elevadas do PARNASO. É plausível relacioná-las a uma compressão horizontal de direção $\mathrm{E}-\mathrm{W}$, conforme descrito no item $e$ (acima), que ocasionaria o soerguimento regional da Serra dos Orgãos.

Campos de esforços e correlações regionais Como não há indicação das idades absolutas dos campos de esforços que atuaram no PARNASO, procurou-se comparar os resultados obtidos com outros estudos desenvolvidos na região (Riccomini 1989, Ferrari 2001, Chiessi 2004, Riccomini et al. 2004, Riccomini et al. 2005).

Assim, pode-se concluir inicialmente pela existência de dois eventos de deformação rúptil, o primeiro de idade neoproterozóica-cambriana e o segundo eocretácea, ambos com SHmáx de direção NE-SW, horizontal. A posição horizontal de SHmáx é assumida, no primeiro caso, em função do caráter escalonado e vertical das juntas, por vezes preenchidas por quartzo e localizadas no interior de veios aplíticos, e corresponderia ao eixo de tensão principal máximo, $\sigma 1$. No segundo caso, assumiu-se também um SHmáx horizontal, correspondente a $\sigma 1$, tendo em vista o paralelismo das juntas com os diques de diabásio e o mecanismo de co- locação determinado, em concordância com trabalhos prévios (Ferrari \& Riccomini 2000, Ferrari 2001). Em ambos os casos o regime tectônico seria transcorrente.

Os eventos posteriores de deformação rúptil produziram estruturas registradas em rochas do embasamento pré-cambriano e também em diques de diabásio eocretáceos. Não há indicações de idades absolutas para os campos de esforços deduzidos a partir das relações entre as famílias de juntas apresentadas nos itens $c, d, e$, e $f$ (acima). O que pode ser inferido é que um SHmáx de direção NNE-SSW, horizontal, seria compatível com as situações descritas nos itens $c$ e $f$, e encontraria correspondência nos eventos de transcorrência sinistral determinados ao longo do Alinhamento Magmático de Cabo Frio, datados do Neocretáceo e do Paleoceno (Riccomini et al. 2005). O mais novo também foi assumido como vigente na formação da depressão da Bacia de Itaboraí (Ferrari 2001).

Tendo em vista a profusa ocorrência de famílias de juntas de direção NE-SW ao longo do tempo é factível que parte destas estruturas estejam associadas ao evento distensivo eoceno de direção NW-SE, considerado como gerador, em caráter regional, do Rift Continental do Sudeste do Brasil (Riccomini et al. 2004). O principal argumento a favor desta proposição é o fato do relevo da porção sul da Serra dos Órgãos encontrar-se compartimentado em blocos alongados e escalonados abatidos para sudeste (Hartwig 2006), analogamente ao descrito por Chiessi (2004) no Maciço Alcalino de Passa Quatro (SP-MG-RJ), neste último caso relacionado ao evento distensivo eoceno, gerador 


\section{ESTAÇÃO 10}

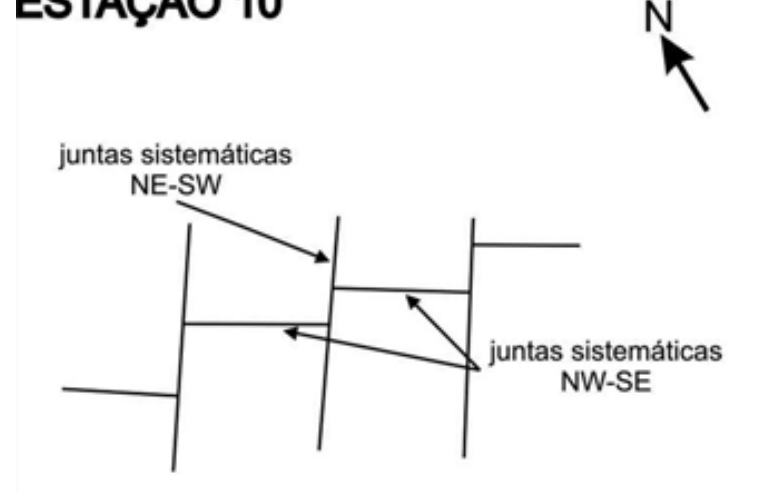

(s/ escala)

ESTAÇĀO 26

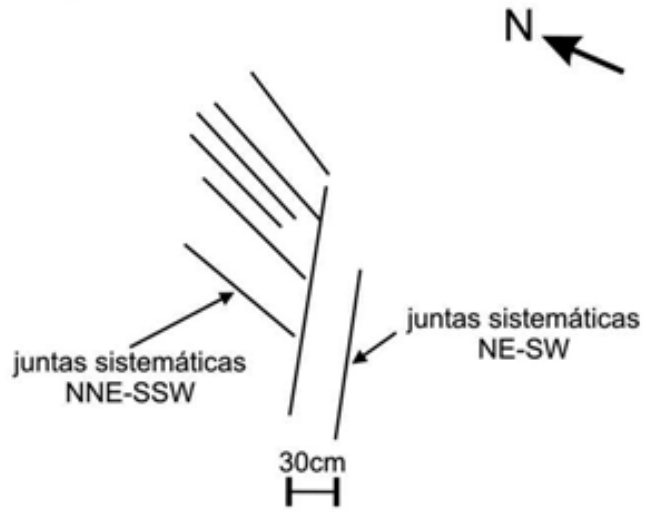

ESTAÇĀO 19

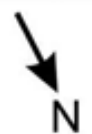
WNW-ESE

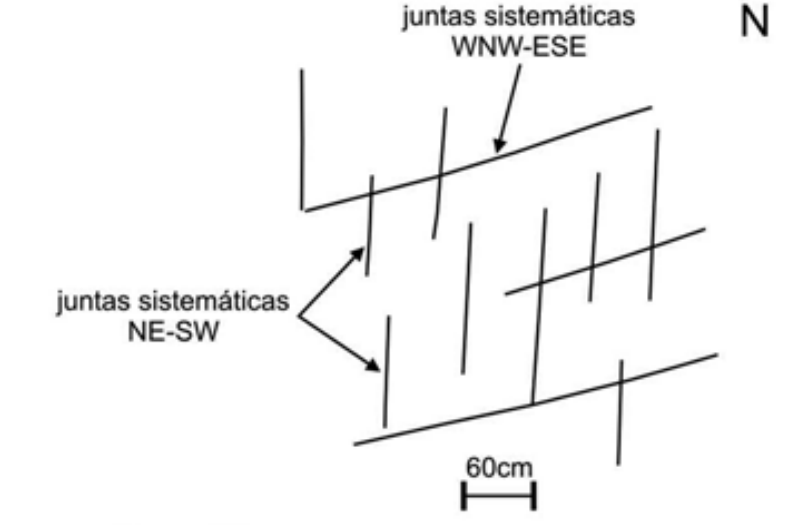

ESTAÇÃO 27

$\mathrm{N}$

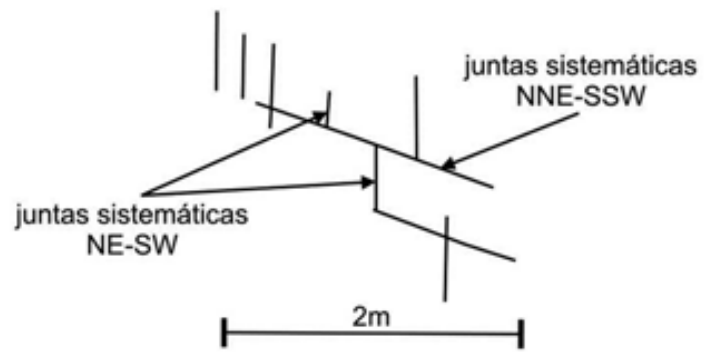

Figura 10 - Croquis ilustrativos das relações identificadas entre as famílias de juntas sistemáticas de direções $N E-S W, N W-S E$, WNW-ESE e NNE-SSW.

do Rift Continental do Sudeste do Brasil (Riccomini et al. 2004). Secundariamente, foram observadas no PARNASO falhas normais conjugadas de direção NE-SW e E-W, que afetam rochas do embasamento. Embora seja uma ocorrência localizada, sua origem encontra afinidade com o mesmo evento tectônico.

Quanto às famílias de juntas de direção NW$\mathrm{SE}$, apesar da carência de informações a respeito de sua relação com outras estruturas, é plausível supor que parte delas tenham sido originadas em algum momento anteriormente ao evento distensivo eoceno de direção NW-SE, considerado como gerador do Rift Continental do Sudeste do Brasil (Riccomini et al. 2004), já que juntas não preenchidas de direção NW-SE são deslocadas por juntas de direção NE-SW (Fig. 10, estação 10). Adicionalmente, Hartwig (2006) associa a origem de parte destas juntas ao evento de transcorrência dextral, com binário E-W de idade pleistocena a holocena descrito por Ferrari (2001) no Gráben da Guanabara, que teria sido responsável, no PARNASO, por uma retomada dos eventos erosivos, com desenvolvimento de drenagens ao longo de lineamentos de direção NW-SE, hoje realçadas pelas facetas trapezoidais observadas ao longo do vale do Rio do Bonfim.

O campo de esforços com SHmáx de direção aproximada E-W, horizontal, descrito nos itens $d$ e e (acima), e também sugerido para as juntas de alívio, encontra correspondência no evento de deformação mais recente do rift, de idade holocena (Riccomini 1989, Salvador \& Riccomini 1995, Riccomini \& Assunção 1999, Riccomini et al. 2004).

Em síntese, as rochas do PARNASO mostram, de um lado, um estilo estrutural distinto, marcado pelo conspícuo desenvolvimento de juntas de alívio, associadas às porções de cimeira deste setor da Serra do Mar e, de outro, estilos estruturais semelhantes e superposição de eventos deformacionais correlacionável aos eventos anteriormente identificados em diferentes compartimentos geomorfológicos do sudeste do Brasil - serras do Mar e da Mantiqueira, Vale do Rio Paraiba do Sul e Depressão da Guanabara (v.g. Riccomini et al. 2004).

CONCLUSÕES A formação das principais estruturas rúpteis verificadas no PARNASO pode estar relacionada a cinco regimes tectônicos superpostos. O primeiro remontaria ao Neoproterozóico-Cambriano e seria caracterizado por uma transcorrência sinistral com binário E-W. Regimes semelhantes foram ativos durante o Eocretáceo e Neocretáceo-Paleoceno, responsáveis, respectivamente, pela colocação do enxame de diques básicos na porção centro ocidental do Estado 
do Rio de Janeiro (Ferrari \& Riccomini 2000), e pelos centros intrusivos e diques de rochas alcalinas dispostos ao longo do Alinhamento Magmático de Cabo Frio (Riccomini et al. 2005).

Um novo regime tectônico teria operado no Eoceno, caracterizado por uma distensão NW-SE, considerada como geradora do Rift Continental do Sudeste do Brasil (Riccomini 1989). Seus principais vestígios no PARNASO seriam a compartimentação do relevo da Serra dos Órgãos, conforme descrito por Hartwig (2006) e, localizadamente, a ocorrência de falhas normais conjugadas de direção NE-SW e E-W, além da provável ocorrência de juntas distensivas de direção NE-SW.

$\mathrm{O}$ último regime tectônico registrado encontra correspondência com uma compressão de direção E-W e idade holocena (Riccomini 1989, Salvador \& Ricco$\operatorname{mini}$ 1995).

O quadro tectônico estabelecido para a região do Parque Nacional da Serra dos Órgãos independe, de modo geral, do contexto geomorfológico regional, e guarda estreita correlação com os estilos estruturais e superposição de eventos de deformação identificados em outras regiões do sudeste do Brasil.

Agradecimentos Os autores externam seus agradecimentos à Fundação de Amparo à Pesquisa do Estado de São Paulo - FAPESP, pelo auxílio financeiro (processo 03/08031-0). Agradecimentos são também devidos aos revisores anônimos da Revista Brasileira de Geociências, pelas sugestões apresentadas, as quais sem dúvida permitiram melhorar a versão original do trabalho. MEH agradece à Coordenação de Aperfeiçoamento de Pessoal de Nível Superior - CAPES pela concessão de bolsa de mestrado. CR é bolsista de produtividade em pesquisa do Conselho Nacional de Desenvolvimento Científico e Tecnológico - CNPq (processo 304649/2005-8).

\section{Referências}

Almeida F.F.M. 1986. Distribuição regional e relações tectônicas do magmatismo pós-paleozóico no Brasil. Rev. Bras. Geoc., 4:325-349.

Almeida F.F.M. 1976. The system of continental rifts bordering the Santos Basin, Brazil. An. Acad. Bras. Ci., 48:15-26.

Almeida F.F.M. 1969. Diferenciação tectônica da Plataforma Brasileira. In: SBG, Congresso Brasileiro de Geologia, 23, Salvador, Anais, p. 29-46.

Almeida F.F.M. 1967. Origem e evolução da plataforma brasileira. Boletim DNPM-DGM, Rio de Janeiro, 241:36p.

Almeida F.F.M. \& Carneiro C.D.R. 1998. Origem e evolução da Serra do Mar. Rev. Bras. Geoc., 28:135-150.

Anderson E.M. 1951. The dynamics of faulting and dyke formation with applications to Britain. Edinburgh, Oliver \& Boyd, 206p.

Angelier J. 1994. Fault slip analysis and palaeostress reconstruction. In: Hancock P.L. (ed.) Continental Deformation. Oxford, Pergamon Press, p. 53-100.

Angelier J. \& Mechler P. 1977. Sur une méthode graphique de recherché des constraints principales également utilizable en tectonique et en séismologie: la méthode des dièdres droits. Bull. Soc. Géol. France, 7:1309-1318.

Asmus H. E. \& Ferrari A. L. 1978. Hipótese sobre a causa do tectonismo cenozóico na região sul do Brasil. In: Carneiro F. (ed.) Aspectos estruturais da margem continental leste e sudeste do Brasil. Rio de Janeiro: PETROBRÁS, Série Projeto REMAC, 4:75-88.

Best M.G. \& Christiansen E.H. 2001. Igneous Petrology. Massachusetts, Blackwell Science, 458p.

Caputo R.A. 1991. A comparison between joints and faults as brittle structures used for evaluation the stress field. Anales Tectonicae, 5:74-84.

Caputo R.A. 1995. Evolution of orthogonal sets of coeval extension joints. Terra Nova, 7:479-490.

Chiessi C.M. 2004. Tectônica cenozóica do Maciço Alcalino de Passa Quatro (SP-MG-RJ). Dissertação de mestrado, Programa de Pós-Graduação em Geologia Sedimentar, Instituto de Geociências, Universidade de São Paulo, São Paulo, 116p.

Davis S. \& Reynolds J. 1996. Structural geology of rocks and regions. New York, Wiley, 776p.

Doblas S.M, Mahecha V., Hoyos M., López-Ruiz J. 1997. Slickenside and fault surface kinematic indicators on active normal faults of the Alpine Betic cordilleras, Granada, southern Spain. J. Struct. Geol.,19:159-170.

Dunne W.M. \& Hancock P.L. 1994. Palaeostress analysis of small-scale brittle structures. In: Hancock P.L. (ed.) Continental Deformation. Oxford, Pergamom Press, p. 101-120.

Feraud G. \& Campredon R. 1983. Geochronology and structural study of Tertiary and Quaternary dikes in southern France and Sardinia: an example of the utilization of dike swarms as paleostress indicators. Tectonophysics, 98:297-325.

Ferrari A.L. 2001. Evolução tectônica do Gráben da Guanabara. Tese de doutoramento, Programa de PósGraduação em Geologia Sedimentar, Instituto de Geociências, Univ. de São Paulo, São Paulo, 412p.

Ferrari A.1., Melo E.F., Vaz M.A., Dalcomo M.T., Brenner T.L., Silva V.P., Nassar W.N. 1981. Bloco Baía da Guanabara: Folhas Itaboraí, Maricá, Saquarema, e Baía de Guanabara. Projeto Carta Geológica do Estado do Rio de Janeiro. Rio de Janeiro: DRM/Geomitec.

Gallagher K., Hawkesworth C.J., Mantovani M.S.M. 1994. The denudation history of the onshore continental margin of SE Brazil inferred from apatite fission track data. J. Geoph. Res.,99(B9):18117-18145.

Geoffroy L., Bergerat F., Angelier J. 1993. Modification d'un champ de contrainte régional par un champ de contraintes magmatique local. Exemple de I'1lle de Skye (Ecosse) au Paléocène. Bull. Soc. Géol. France, 164:541-552.

Gontijo A.H.F. 1999. Morfotectônica do Médio Vale do Rio 
Paraíba do Sul: região da Serra da Bocaina, leste do Estado de São Paulo. Tese de doutoramento, Instituto de Geociências e Ciências Exatas, Universidade Estadual Paulista, Rio Claro, 265 p.

Hancock P.L. 1985. Brittle microtectonics: principles and practice. J. Struct. Geol., 7:437-457.

Hancock P. \& Engelder T. 1989. Neotectonic joints. Geol. Soc. Am. Bull., 10:1197-1208.

Hartwig M.E. 2006. Tectônica Rúptil Mesozóico-Cenozóica na região da Serra dos Órgãos, RJ. Dissertação de mestrado, Programa de Pós-Graduação em Geoquímica e Geotectônica, Instituto de Geociências, Universidade de São Paulo, São Paulo, 117p.

Hasui Y. \& Oliveira M.A.F. 1984. Província Mantiqueira Setor Central. In: Almeida F.F.M. \& Hasui Y. (eds.) $O$ Pré-Cambriano do Brasil. São Paulo, Edgard Blucher, p. 308-344.

Hasui Y., Carneiro C.D.R., Coimbra A.M. 1975. The Ribeira Folded Belt. Rev. Bras. Geoc., 5:257-266.

Hasui Y., Gimenez A.F., Melo M.S. 1978. Sobre as bacias tafrogênicas continentais do sudeste brasileiro. In: SBG, Congresso Brasileiro de Geologia, 30, Recife, Anais, p. 382-391.

Heilbron M. \& Machado N. 2003. Timing of terrane accretion in the Neoproterozoic-Eopaleozoic Ribeira orogen (SE Brazil). Precambrian Res., 125:87-112.

Hiruma S.T. 2007. Significado morfotectônico dos planaltos isolados da Bocaina. Tese de doutoramento, Programa de Pós-Graduação em Geoquímica e Geotectônica, Instituto de Geociências, Universidade de São Paulo, São Paulo, 205p.

Hiruma S.T., Riccomini C., Modenesi-Gauttieri M.C. 2001. Neotectônica no Planalto de Campos do Jordão, SP. Rev. Bras. Geoc., 31:375-384.

King L. 1956. A Geomorfologia do Brasil Oriental. Rev. Bras. Geogr., 18:147-266.

Melo M.S., Riccomini C., Hasui Y., Almeida F.F.M., Coimbra A.M. 1985. Geologia e evolução do Sistema de Bacias Tafrogênicas Continentais do sudeste do Brasil. Rev. Bras. Geoc., 15:193-201.

Modenesi-Gauttieri M.C., Hiruma S.T., Riccomini C. 2002. Morphotectonics of a high plateau on the northwestern flank of the Continental Rift of Southeastern Brazil. Geomorphology, 43:257-271.

Penha H., Ferrari A.L., Ribeiro A., Amador E.S., Pentagna F.V., Junho M.C.B., Brenner T.L. 1979. Projeto Folha Petrópolis. Projeto Carta Geológica do Estado do Rio de Janeiro. Rio de Janeiro: DRM/UFRJ.

Penha H., Ferrari A.L., Junho M.C.B., Souza S.L.A., Brenner T.L. 1981. Projeto Folha Itaipava. Projeto Carta Geológica do Estado do Rio de Janeiro. Rio de Janeiro: DRM/UFRJ.

Petit J.P. 1987. Criteria for the sense of movement on fault surfaces in brittle rocks. J. Struct. Geol., 9:597-608.

Pinto C.P., Serpa J.C., Dutra J.E.B., Hettich M., Andrade N.T. 1980. Folhas Anta, Duas Barras, Teresópolis e Nova Friburgo. Projeto Carta Geológica do Estado do Rio de Janeiro. Rio de Janeiro: DRM/Geosol.

Price N. J. 1966. Fault and joint development in brittle and semi-brittle rock. Oxford, Pergamom Press, 175p.
Ramsay J.G. \& Ruber M.I. 1987. The techniques of modern structural geology: Folds and fractures. London, Academic Press, vol. 2, 700p.

Riccomini C. 1989. O Rift continental do sudeste do Brasil. São Paulo. Tese de doutoramento, Programa de Pós Graduação em Geologia Sedimentar, Instituto de Geociências, Univ. de São Paulo, São Paulo, 256p.

Riccomini C. \& Asumpção M. 1999. Quaternary tectonics in Brazil. Episodes, 22:221-225.

Riccomini C., Sant'Anna L.G., Ferrari A.L. 2004. Evolução geológica do Rift Continental do Sudeste do Brasil. In: Mantesso Neto V., Bartorelli A., Carneiro C.D.R. Brito Neves B.B. (orgs.) Geologia do Continente Americano: evolução da obras de Fernando Flávio Marques de Almeida. São Paulo, Beca, p. 383-405.

Riccomini C., Velázquez V.F., Gomes C.B. 2005. Tectonic controls of the mesozoic and cenozoic alkaline magmatism in central-southeastern Brazilian Platform. In: Comin-Chiaramonti P. \& Gomes C.B. (eds.) Mesozoic to Cenozoic alkaline magmatism in the Brazilian Platform. São Paulo, Edusp/Fapesp, p. 31-55.

Rickwood P.C. 1990. The anatomy of a dyke and the determination of propagation and magma flow directions. In: Parker J., Rickwood P.C., Tucker D.H. (eds.) Mafic dykes and emplacement mechanisms. Rotterdam, Balkema, p. 81-100.

Ruellan F. 1944. A evolução geomorfológica da Baía da Guanabara e das regiões vizinhas. Rev. Bras. Geogr., 4:445-508.

Salvador E.D. \& Riccomini C. 1995. Neotectônica da região do Alto Estrutural de Queluz (SP-RJ, Brasil). Rev. Bras. Geoc., 25:151-164.

Schäffer W.B. \& Prochnow M. 2002. A Mata Atlântica e Você. Brasília, APREMAVI, 155p.

Stewart I.S. \& Hancock P.L. 1994. Neotectonics. In: Hancock P.L. (ed.) Continental Deformation. Oxford, Pergamon Press. p. 370-409.

Trouw R.A.J., Heilbron M., Ribeiro A., Paciullo F., Valeriano C.M., Valeriano C.M., Almeida J.C.H., Tupinambá M., Andreis R.R. 2000. The Central Segment of the Ribeira Belt. In: Cordani U.G., Milani E.J., Thomaz Filho A., Campos D.A. (eds.) Tectonic Evolution of South America. Rio de Janeiro, International Geological Congress, $31^{\text {st }}$, p. 287-310.

Zalán P.V. 2004. Evolução Fanerozóica das Bacias Sedimentares Brasileiras. In: Mantesso Neto V., Bartorelli A., Carneiro C.D.R. Brito Neves B.B. (orgs.) Geologia do Continente Americano: evolução da obras de Fernando Flávio Marques de Almeida. São Paulo: Beca, p. 595-612.

Zalán P.V. \& Oliveira J.A.B. 2005. Origem e evolução estrutural do Sistema de Riftes Cenozóicos do Sudeste do Brasil. Bol. Geoc. Petrobrás, 13:269-300.

Zoback M.L. 1992. First- and Second-Order Patterns of Stress in the Litosphere: The World Stress Map Project. J. Geoph. Res., 97(B8):11.703-11.728.

Manuscrito ID 11487 Submetido em 12 de junho de 2008 Aceito em 14 de agosto de 2009 